\title{
Designer D-form self-assembling peptide scaffolds promote the proliferation and migration of rat bone marrow-derived mesenchymal stem cells
}

\author{
SHUO CHEN, AO ZHOU, BIN HE, WEIKANG ZHAO, XIAOJUN CHEN and DIANMING JIANG
}

\author{
Department of Orthopedics, The First Affiliated Hospital of Chongqing Medical University, Chongqing 400016, P.R. China
}

Received May 18, 2016; Accepted June 23, 2017

DOI: 10.3892/ijmm.2017.3056

\begin{abstract}
Self-assembling peptide (SAP) nanofiber hydrogel scaffolds have become increasingly important in tissue engineering due to their outstanding bioactivity and biodegradability. However, there is an initial concern on their long-term clinical use, since SAPs made of L-form amino acid sequences are sensitive to enzymatic degradation. In this study, we present a designer SAP, D-RADA16, made of all D-amino acid. We investigated the nanofiber morphology of D-RADA16, its potential for the culture of bone marrow-derived mesenchymal stem cells (BMSCs), and the proteolytic resistance of the biomaterial. The results revealed that D-RADA16 exhibited stable $\beta$-sheets and formed interwoven nanofiber scaffolds in water. D-RADA16 and L-RADA16 hydrogel scaffolds were both found to promote the proliferation and migration of rat BMSCs in the 3D cell culture microenvironment. Furthermore, the D-RADA16 scaffolds exhibited a higher proteolytic resistance against proteinase $\mathrm{K}$ than the L-RADA16 scaffolds. These observations indicate that D-RADA16 hydrogel scaffolds have excellent bioactivity, biocompatibility and biostability, and thus may serve as promising candidates for long-term application in vivo.
\end{abstract}

\section{Introduction}

Recently, various types of biomaterials have been developed for tissue engineering aims. Used as scaffolds, biomaterials should provide a suitable microenvironment for the cells to survive, proliferate, differentiate and migrate (1). Ideal biomimetic scaffolds are required to possess a series of characteristics: excellent biocompatibility, low immunogenicity, appropriate porosity, permeability and mechanical elasticity, and they need to be

Correspondence to: Professor Dianming Jiang, Department of Orthopedics, The First Affiliated Hospital of Chongqing Medical University, 1 Youyi Road, Yuzhong, Chongqing 400016, P.R. China E-mail: jdm571026@126.com

Key words: self-assembly, peptide, D-amino acid, chirality, biomaterial, tissue engineering easily synthesized (2). Hydrogels, as scaffolding biomaterials, are water-swollen polymeric networks, but they cannot dissolve in water. The attractive features to swell under physiological conditions make them ideal candidates for tissue engineering applications (3-7). Hydrogels possess a 3D network structure with physical or chemical cross-linking. This insoluble crosslinked gel-network possesses the ability to release active agents and biomolecules effectively. Due to the high water content, hydrogels generally exhibit good biocompatibility and high permeability for oxygen, nutrition supply, bioactive factors and waste products exchange from cells. That is why hydrogels are regarded as ideal scaffolds for use in 3D cell culture (5-9). In addition, most hydrogels can be used as injectable scaffolds for a variety of applications (10-12). Based on the polymer origin, hydrogels can be classified into three major types: natural, synthetic and synthetic/natural hybrid hydrogels. As important natural hydrogel biomaterials, self-assembling peptides (SAPs) have emerged as promising scaffolds for tissue engineering applications over the past two decades.

Among the SAPs, the most widely studied is RADA16 which consists of 16 alternating hydrophobic and hydrophilic amino acids. RADA16 spontaneously assembles into interwoven nanofiber scaffolds in water and subsequently forms hydrogel $(13,14)$. Therefore, RADA16 supports a true $3 \mathrm{D}$ culture environment with high aspect ratio nanofibers that mimic the extracellular matrix (ECM) for cell growth, migration and differentiation (15-17). Moreover, RADA16 is easy to functionalize using biologically active epitopes and enhances the bioactivity (18-22). The functionalized RADA16 scaffolds have been found to be versatile in bone, cartilage, neural and heart tissue regeneration, wound healing, angiogenesis, osteosis and hemostasis (23-28).

Despite the advantages of RADA16 mentioned, the biomaterial scaffolds made of L-amino acids may degrade more rapidly in vivo by proteases than desired, and such an instability limits its range of applications for achieving long-term biostability (29). Recently, active efforts have been made to maintain the stability of SAP from enzymatic decomposition in vivo, and $\mathrm{D}$-amino acid possesses remarkable potentiality to address this issue (30-32). However, preliminary studies have suggested that D-amino acid in the peptides backbone causes conformational changes of the peptides, evidently disrupting the self-assembly process, and decreasing the flexibility of the hydrogels (29). We hereby designed a SAP, D-RADA16, which 
was made of only D-amino acids to avoid the disruption of supramolecular self-assembly.

The present study focused on evaluating whether D-RADA16 forms stable $\beta$-sheet structure in water and further self-assembles into interweaving nanofiber scaffolds, providing a similar 3D microenvironment with which to promote the proliferation and migration of rat bone marrow-derived mesenchymal stem cells (BMSCs), similar to L-RADA16. Additionally, the bioactivity and biostability of D-RADA16 was assessed. We first confirmed the self-assembling ability of D-RADA16 by circular dichroism (CD) spectroscopy and transmission electron microscopy (TEM). Various concentrations of both peptides were examined by MTT assay to investigate the optimal concentration for BMSC proliferation in vitro. BMSCs were cultured in the SAP hydrogels for osteoblastic differentiation and migration observation. Lastly, we appraised the enzymatic stability of the SAPs with proteinase K. Our results suggested that D-RADA16 hydrogel scaffolds exhibited satisfactory bioactivity and biostability, which may ultimately broaden the scope of long-term applications in vivo.

\section{Materials and methods}

Peptide synthesis and purification. The SAP scaffolds, RADA16 (AcN-RADARADARADARADA-CONH2), were custom-synthesized (Shanghai Bootech Bioscience and Technology Corp., Ltd., Shanghai, China) through direct solid phase synthesis, purified by high-performance liquid chromatography (HPLC) (Thermo Electron Corp., Waltham, MA, USA), and characterized by mass spectroscopy (Waters Corp. Milford, MA, USA). The purity of D-RADA16 and L-RADA16 was 95.90 and $95.54 \%$, respectively. The peptide D-RADA16 sequence contained all D-amino acids, and the L-RADA16 sequence contained all L-amino acids. Solutions of the peptides were prepared at concentrations of $1.0-10.0 \mathrm{mg} / \mathrm{ml}$ $(0.1-1.0 \%, \mathrm{w} / \mathrm{v})$ in water $(18 \mathrm{M} \Omega \cdot \mathrm{cm}$; Millipore Milli-Q System, Billerica, MA, USA) and stored at $4^{\circ} \mathrm{C}$ before use.

Reagents. Dulbecco's modified Eagle's medium/F12 (DMEM/ F12), fetal bovine serum (FBS) and $0.25 \%$ trypsin/EDTA were purchased from HyClone (Logan, UT, USA). Penicillin/streptomycin aqueous solution, MTT assay, $\beta$-glycerophosphate, dexamethasone, ascorbic acid and proteinase $\mathrm{K}$ were all obtained from Sigma Chemical Co. (St. Louis, MO, USA). The antibodies used for western blot analysis were all purchased from Abcam PLC (Cambridge, UK). Calcein-AM was purchased from Enzo Life Sciences, Inc. (Farmingdale, NY, USA).

Molecular models and chemical structures. Molecular models and chemical structures of the chiral peptides were constructed using free modeling software (Hyperchem professional version 7.5, http://www.hyper.com) and chemical structure drawing software (ChemDraw Ultra 14.0) respectively.

CD spectroscopy. The samples consisted of $1.0 \mathrm{mg} / \mathrm{ml}$ aqueous stock solutions of peptide and were adjusted to $0.17 \mathrm{mg} / \mathrm{ml}$ in solution in water. A sample of $400 \mu \mathrm{l}$ was added in a CD cuvette with a $2 \mathrm{~mm}$ path-length. Measurements were carried out on an J-810 CD spectrometer (JASCO International Co., Tokyo, Japan). The samples were incubated at $20^{\circ} \mathrm{C}$, equilibrated for
$30 \mathrm{sec}$, measured from 190 to $260 \mathrm{~nm}$, averaged over $3 \mathrm{sec}$ through the entire wavelength range, and took the $190-250 \mathrm{~nm}$ analysis.

TEM. TEM samples $(2.0 \mathrm{mg} / \mathrm{ml})$ were prepared at $25^{\circ} \mathrm{C}$. A micropipet was used to load an aliquot of $5 \mu 1$ of peptide solution to a carbon coated copper grid. The excess solution was removed by a piece of filter paper. The samples were dyed by $10 \mu \mathrm{l}$ uranyl acetate for $30 \mathrm{sec}$ and dried overnight in a desiccator and then conducted on a Tecnai G2 F20 system (FEI Company, Hillsboro, OR, USA) operating at $200 \mathrm{kV}$.

Preparation and culture of BMSCs. A total of 18 male Sprague-Dawley rats, 4 weeks of age, were used in this study. The rats were obtained from the Laboratory Animal Center of Chongqing Medical University, Chongqing, China. BMSCs were isolated from the bone shaft of the rats according to the technique reported by Lennon et al (33) and the protocol was approved by the Ethics Committee of the First Affiliated Hospital of Chongqing Medical University (permit no. 2014-201058). Briefly, the rats were sacrificed by an overdose of isoflurane. The bone marrow was flushed out from the femurs by a syringe (21-gauge needle) with $5 \mathrm{ml}$ of DMEM/F12 containing $10 \%$ FBS and $1 \%$ penicillin/streptomycin $(200 \mathrm{U} /$ $\mathrm{ml}$ ). The cell suspension was placed into two T-25 flasks (Nest Biotechnology Co., Jiangsu, China) and cultured at $37^{\circ} \mathrm{C}$ in an atmosphere with $95 \%$ humidity and $5 \% \mathrm{CO}_{2}$. The medium was changed on the second day of culture and every 3 days thereafter. When the cells became subconfluent, they were detached from the flask by treatment with an aqueous solution of $0.25 \%$ trypsin/EDTA for $3 \mathrm{~min}$ at $37^{\circ} \mathrm{C}$. The cells were normally passaged at a density of $2 \times 10^{4}$ cells $/ \mathrm{cm}^{2}$. Cells at the third passage at subconfluence were used in all the experiments.

Three-dimensional cell culture technique using the chiral $R A D A 16$. In the case of cell viability assay, the chiral scaffolds at various concentrations $(1.25,2.5,5.0$ and $10.0 \mathrm{mg} / \mathrm{ml})$ were prepared as L-RADA16 and D-RADA16. Each of the solution was sonicated for $30 \mathrm{~min}$ and loaded $(5 \mu \mathrm{l})$ in the bottom of 96-well culture plates (Nest Biotechnology Co.). Subsequently, $50 \mu \mathrm{l}$ medium were slowly added to the solution to induce gelation. The hydrogel formed in several minutes, and was rinsed twice with medium to equilibrate the gel to physiological $\mathrm{pH}$. The hydrogels were thyen incubated overnight at $37^{\circ} \mathrm{C}$ with $5 \% \mathrm{CO}_{2}$ until cell seeding. Lastly, $50 \mu \mathrm{l}$ of BMSCs cells $\left(4 \times 10^{4}\right.$ cells $\left./ \mathrm{ml}\right)$ in DMEM/F12 mixture were seeded in each well on top of the various hydrogels in 96-well culture plates, where they were able to settle into the nanofiber scaffolds. The $3 \mathrm{D}$ cell cultures were maintained in an incubator at $37^{\circ} \mathrm{C}$ with $5 \% \mathrm{CO}_{2}$ for 3,5 or 7 days and the medium was changed every 2-3 days if necessary.

In the case of differentiation assay, $500 \mathrm{ml}$ of peptide solution $(5 \mathrm{mg} / \mathrm{ml})$ were directly loaded into a 6 -well culture plate (Nest Biotechnology Co.) and then stimulated to self-assemble following the addition of $1 \mathrm{ml}$ culture medium in each well. During the following $30 \mathrm{~min}$, the medium was changed twice to equilibrate the growth environment to physiological $\mathrm{pH}$ and then incubated for $2 \mathrm{~h}$ at $37^{\circ} \mathrm{C}$ with $5 \% \mathrm{CO}_{2}$ for gelation. Subsequently, $200 \mu \mathrm{l}$ of BMSCs ( $1 \times 10^{6}$ cells $\left./ \mathrm{ml}\right)$ in DMEM/F12 mixture were seeded on top of the hydrogel. The cells were cultured in the differentiation media consisting of $10 \mathrm{mM}$ 
$\beta$-glycerophosphate, $10 \mathrm{nM}$ dexamethasone, $50 \mu \mathrm{g} / \mathrm{ml}$ ascorbic acid. The media were changed every 3 days.

In the case of the migration assay, cell culture Transwell inserts (Corning Inc., Corning, NY, USA) were used for peptide hydrogelation as previously reported (20). Briefly, the inserts were placed in a 24-well culture plate (Nest Biotechnology Co.) with $400 \mu$ l culture medium in the lower chambers of each well. One hundred microliters of peptide solutions solution $(5 \mathrm{mg} / \mathrm{ml})$ were directly loaded into the upper chamber of each well. The medium was changed twice and incubated as described in the differentiation assay. To prevent the drying of the surfaces of the formed hydrogels, $400 \mathrm{ml}$ of culture medium were gently layered onto the hydrogels and then incubated overnight at $37^{\circ} \mathrm{C}$ with $5 \% \mathrm{CO}_{2}$. Two hundred microliters of BMSCs (1x10 $10^{5}$ cells/ $\mathrm{ml}$ ) in DMEM/F12 mixture were seeded on top of the peptide gel in the inserts. The cells were cultured in the maintenance medium (DMEM/F12 containing $10 \%$ FBS and $1 \%$ penicillin/ streptomycin) and this was changed every 3 days by removing $400 \mu \mathrm{l}$ of medium from the lower chambers and adding $400 \mu \mathrm{l}$ of fresh medium inside the upper chambers. The cells were harvested at planned time points for analysis.

In addition, a conventional $2 \mathrm{D}$ cell culture method (tissue culture plate) was used to culture the BMSCs to examine their proliferation and migration as a control.

Cell viability assay. To determine the extent of the proliferation of the cells seeded on the chiral scaffolds, a well-characterized quantitative assat, 3-(4,5-dimethylthiazol-2yl)-2,5-diphenyl tetrazolium bromide test (MTT) assay was performed. Briefly, after the cells were incubated for 3,5 or 7 days, the medium was removed and the cells were treated with $20 \mu \mathrm{l}$ of $5 \mathrm{mg} / \mathrm{ml}$ MTT solution. Follwoing incubation at $37^{\circ} \mathrm{C}$ for $4 \mathrm{~h}$, the MTT solution was removed and $150 \mu \mathrm{l}$ of dimethyl sulfoxide (DMSO) were added to dissolve the insoluble formanzan crystals. After $20 \mathrm{~min}$, the absorbance was read at $490 \mathrm{~nm}$ using a Multiskan Spectrum spectrophotometer (Thermo Fisher Scientific, Vantaa, Finland). Since some hydrogels may dissolve partially when removing the formanzans, we tested the hydrogels without cells to confirm any possible bias in the absorbance measurements, and found no significant differences between any of the tested scaffolds and the scaffolds without cells (data not shown). In order eliminate dye absorbance derived from medium, a background group was added to the analysis groups. Three independent experiments comprising 4 replicates each were performed.

Western blot analysis. At the end of the culture period, the cells were lysed for $30 \mathrm{~min}$ in ice-cold RIPA buffer (BCA; Beyotime, Jiangsu, China). The cell lysate was centrifuged at 12,000 rpm for $20 \mathrm{~min}$ at $4^{\circ} \mathrm{C}$. The supernatants were heated at $100^{\circ} \mathrm{C}$ for $5 \mathrm{~min}$ in $5 \mathrm{X}$ loading buffer (Beyotime). Equal aliquots of protein $(40 \mu \mathrm{g})$ were loaded onto $10 \%$ sodium dodecyl sulfate-polyacrylamide gel electrophoresis (SDS-PAGE) and transferred onto PVDF membranes $(0.45 \mu \mathrm{m})$. The membranes were blocked for $1 \mathrm{~h}$ at room temperature by $5 \%$ non-fat milk, washed 3 times and incubated with primary antibodies [anti-osteopontin (OPN; ab8448, 1:1,000), anti-runt-related transcription factor 2 (RUNX2) (ab23981, 1:1,000) and anti-glyceraldehyde 3-phosphate dehydrogenase (GAPDH) (ab8245, 1:2,000) (all from Abcam PLC)] at $4^{\circ} \mathrm{C}$ overnight. The membranes were then washed in TBST 3 times and incu- bated with corresponding horseradish peroxidase conjugated secondary antibody (goat anti-rabbit) for $1 \mathrm{~h}$ at room temperature. The blots were developed by a chemiluminescence kit (Beyotime) on a Bio-Rad imaging system.

$3 D$ cell migration assay. Cell culture was performed as described above. After being cultured for 7 days, the cells on the hydrogels were examined using calcein-AM staining, an indicator of intracellular esterase activity which stains whole living cells, according to the manufacturer's instructions. Briefly, cells on the chiral scaffolds of the inserts were washed twice using phosphate-buffered saline (PBS). Subsequently, $4 \mu \mathrm{M}$ calcein-AM solution were added to the insert and incubated for $30 \mathrm{~min}$ within the incubator at $37^{\circ} \mathrm{C}$ with $5 \% \mathrm{CO}_{2}$. The inserts were rinsed twice with PBS and multiple images were obtained with confocal laser scanning microscopy (Nikon A1R; Nikon, Tokyo, Japan) through z-stack scanning mode with a step size of $3 \mu \mathrm{m}$. The fiber diameters were examined using Image-Pro Plus software (version 6.0) analysis software. For each image, 200 fibers were measured and recorded.

Peptide degradation by proteinase $K$. We dissolved $1 \mathrm{mg}$ of peptide in $5 \mathrm{ml} 0.01 \mathrm{M}$ PBS, and $0.25 \mathrm{mg}$ proteinase $\mathrm{K}$ was added to the solution, resulting in a 0.2 and $0.05 \mathrm{mg} / \mathrm{ml}$ concentration of peptide and proteinase $\mathrm{K}$, respectively. The samples, consisting of hydrogels and proteinase $\mathrm{K}$, were incubated at $37^{\circ} \mathrm{C}$ on shaking tables for $1-24 \mathrm{~h}$ and $400 \mu \mathrm{l}$ aliquots were taken after $1,2,4,6,8,12$ and $24 \mathrm{~h}$. The enzymatic reaction was terminated by the addition of phenylmethanesulfonylfluoride (PMSF) and the concentration of the intact peptide was analyzed by HPLC (LCMS-2020; Shimadzu, Kyoto, Japan) using following conditions: column: Venusil XBP C18, $5 \mu \mathrm{m}$, 4.6x50 mm (Agela, Tianjin, China); sample injection volume: $100 \mu \mathrm{l}$; gradient elution: A, $0.035 \%$ trifluoroacetic acid (TFA) in water; and B, $0.035 \%$ TFA in acetonitrile/water (80:20, vol/ vol). A gradient of $10-100 \% \mathrm{~B}$ in $10 \mathrm{~min}$ was conducted. The experiment was conducted in 3 replicates.

Statistical analysis. Data are presented as the means \pm standard deviation (SD) and compared between any 2 groups using a two-tailed paired t-test. The differences between multiple group comparisons were made by one-way ANOVA and followed by multiple pairwise comparisons using Fisher's least significant difference (LSD) test. Significance levels were set to $\mathrm{P}<0.05$ for all comparisons.

\section{Results}

Hydrogelation of L-RADA16 and D-RADA16. We observed the formation of hydrogelation after $30 \mathrm{~min}$. Both of the peptide solutions were obtained by dissolving the peptide powder in water at the concentration of $10 \mathrm{mg} / \mathrm{ml}$. As shown in Fig. 1A, we found that the introduction of D-amino acids did not effect on the gelation behavior of the SAP solution.

Molecular models and chemical structures of L-RADA16 and $D$-RADA16. We present two molecular models (Fig. 2A and B) and chemical structures (Fig. 2C) of L-RADA16 and D-RADA16 peptides. These peptides have an identical sequence, but are composed of amino acids of a different 
A

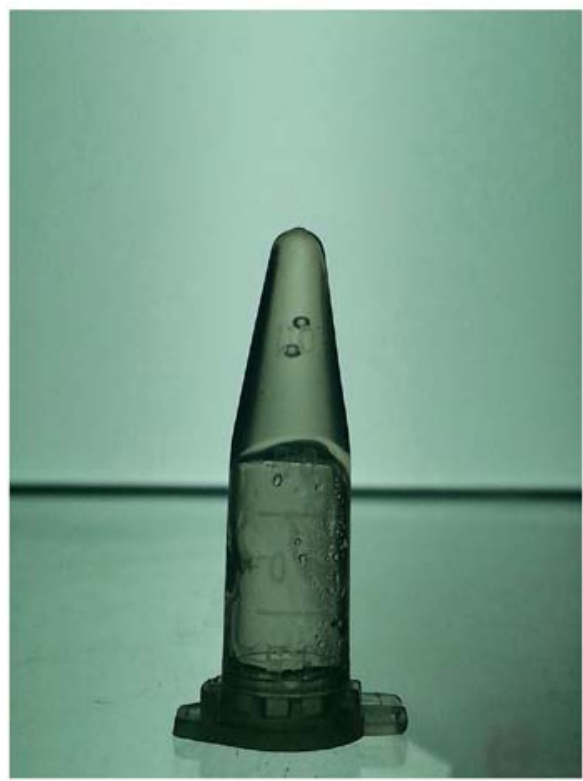

B

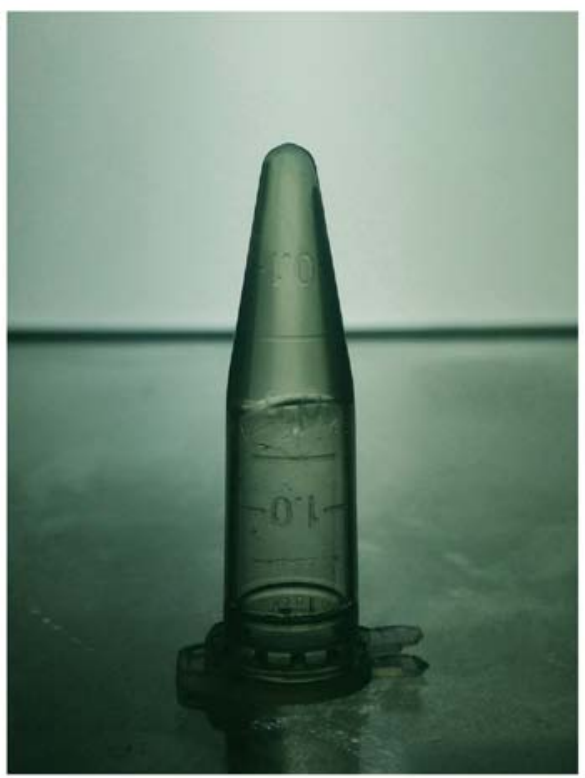

Figure 1. Image of the chiral self-assembling peptide (SAP) hydrogel: (A) L-RADA16; (B) D-RADA16.

A

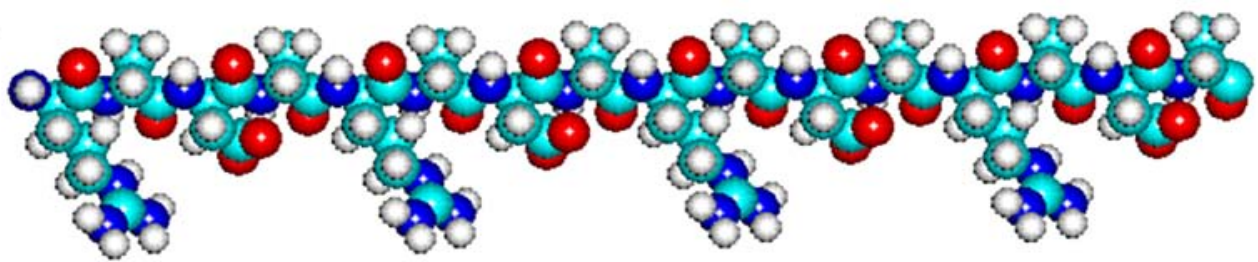

B

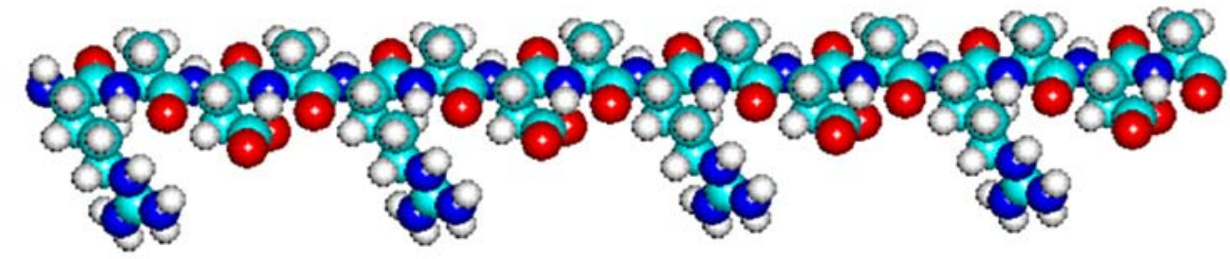

C

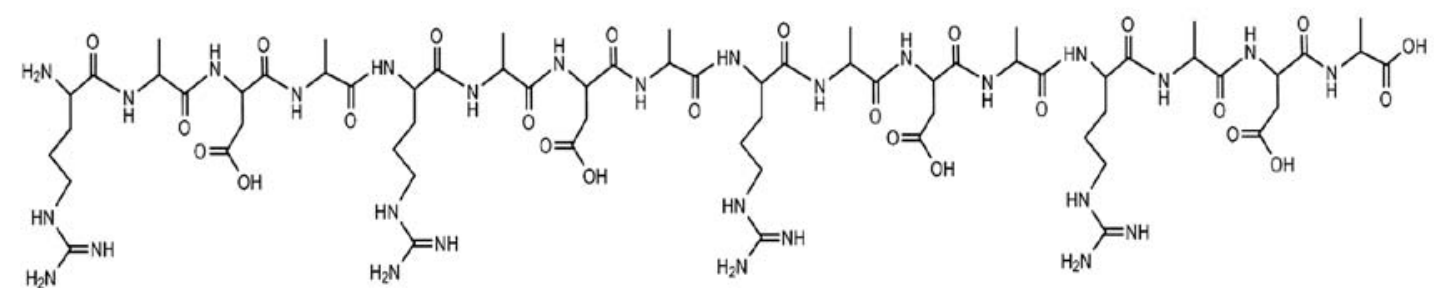

Figure 2. Molecular models of the chiral peptides. (A) L-RADA16; (B) D-RADA16. (C) Chemical structures of the chiral peptides. All peptides are modeled in the extended $(\mathrm{N} \rightarrow \mathrm{C})$. Color code: hydrogen, white; carbon, cyan; oxygen, red; and nitrogen, blue.

chiral form: all L-amino acids in L-RADA16 and all D-amino acids in D-RADA16. The pair of RADA16 structures appears similar, but some of their properties are quite diverse.

Structural characterizations of the chiral RADA16. The secondary structures of the chiral RADA16 peptides were examined by CD measurements. From a previous study, L-RADA16 is known to form a stable $\beta$-sheet structure (21). In this study, CD spectroscopy revealed that the D-RADA16 was not only able to adopt a typical $\beta$-sheet structure, but also had an inverted $\beta$-sheet spectrum with a positive peak at $216.8 \mathrm{~nm}$ and a negative peak at $193.1 \mathrm{~nm}$ (Fig. 3), which was almost a mirror image of the L-RADA16 spectrum which had an $\beta$-sheet spectrum with a positive peak at $195.7 \mathrm{~nm}$ and a negative peak at $216.2 \mathrm{~nm}$. This suggests that D-RADA16 is the enantiomer of L-RADA16.

Self-assembling nanofiber morphology of the chiral peptides. A previous study demonstrated that the peptide L-RADA16 possesses the ability of self-assembly into interwoven nanofibers (21). In the present study, we wished to determine whether D-RADA16 made of D-amino acids would trigger self-assembly process and form well-ordered nanofibers. TEM morphological 


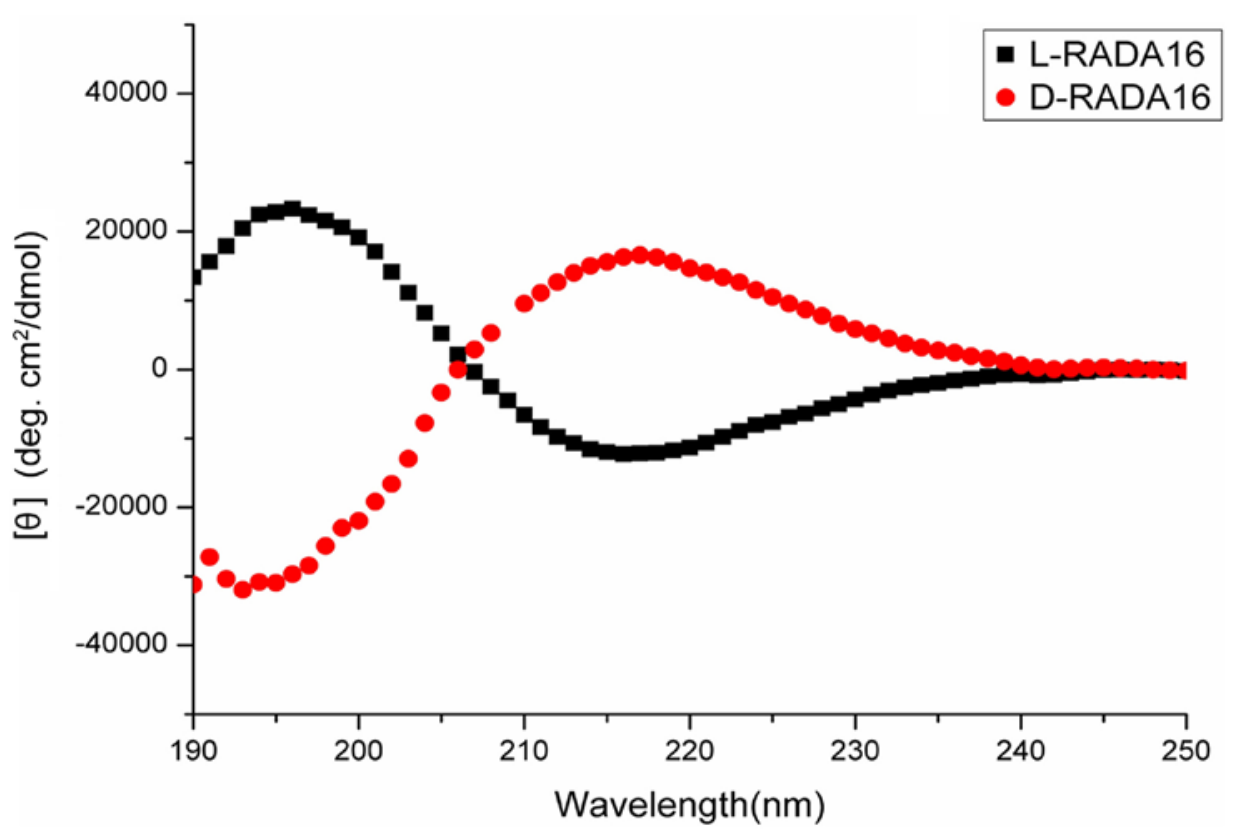

Figure 3. Typical CD spectra of the chiral peptides in PBS at $20^{\circ} \mathrm{C}$. The $\mathrm{x}$-axis represents the wavelength in $\mathrm{nm}$; the $\mathrm{y}$-axis represents the mole residue ellipticity $[\theta]$.
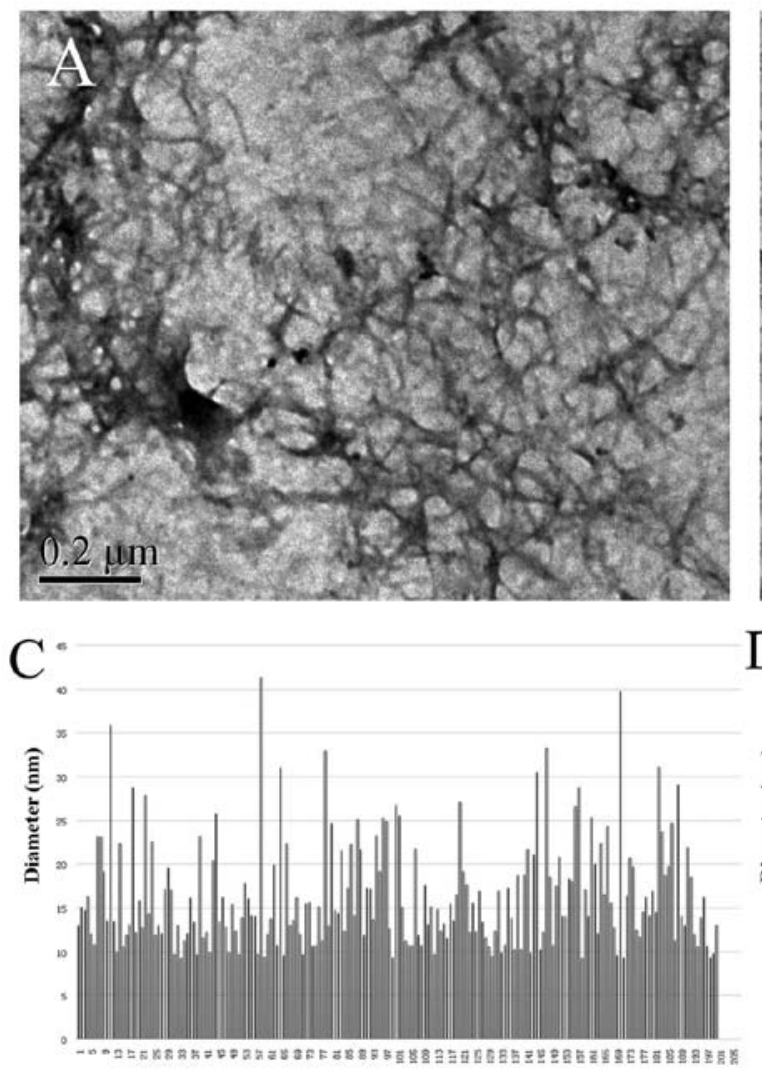

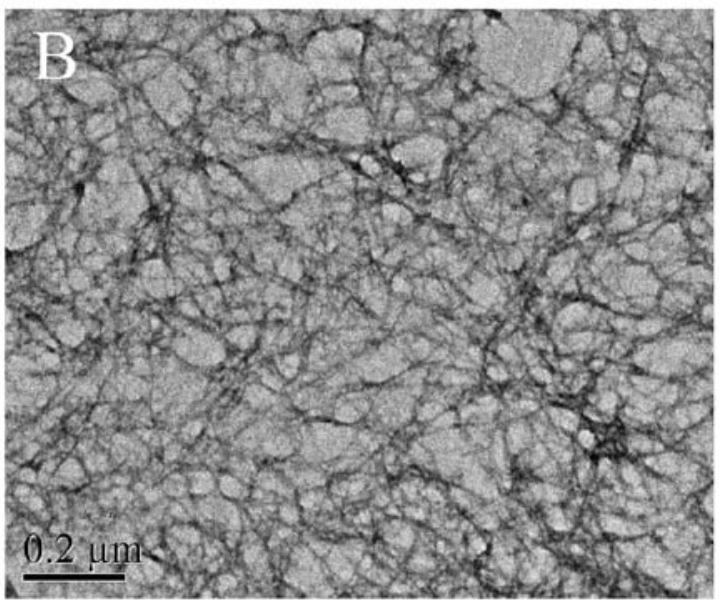

$\mathrm{D}^{-}$

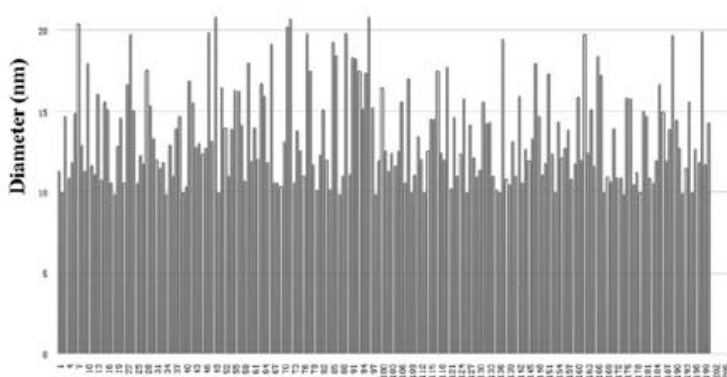

Figure 4. Transmission electron microscopy (TEM) images of $2.0 \mathrm{mg} / \mathrm{ml}$ self-assembling peptide (SAP) nanofibers in the hydrogel: (A) L-RADA16; (B) D-RADA16. We also examined the diameters of the nanofibers (C) L-RADA16; (D) D-RADA16.

analyses denoted that D-RADA16 indeed formed ordered nanofibers ranging in length from several hundred nanometers to a few microns, and the diameters of nanofibers assembled from L-RADA16 and D-RADA16 were $16.34 \pm 6.13$ and $13.52 \pm 2.94 \mathrm{~nm}$, respectively (Fig. 4). These observations are in agreement with those of previous findings $(34,35)$.
Cell viability. BMSCs were grown on the chiral scaffolds at various concentrations from 1.25 to $10 \mathrm{mg} / \mathrm{ml}$. The cell proliferation rate of the $3 \mathrm{D}$ cell culture method and the conventional $2 \mathrm{D}$ cell culture method as a control were performed for 3 days (Fig. 5A). We noted that there were no significant difference in the proliferation rates between the chiral scaffolds at each concentration after 
A

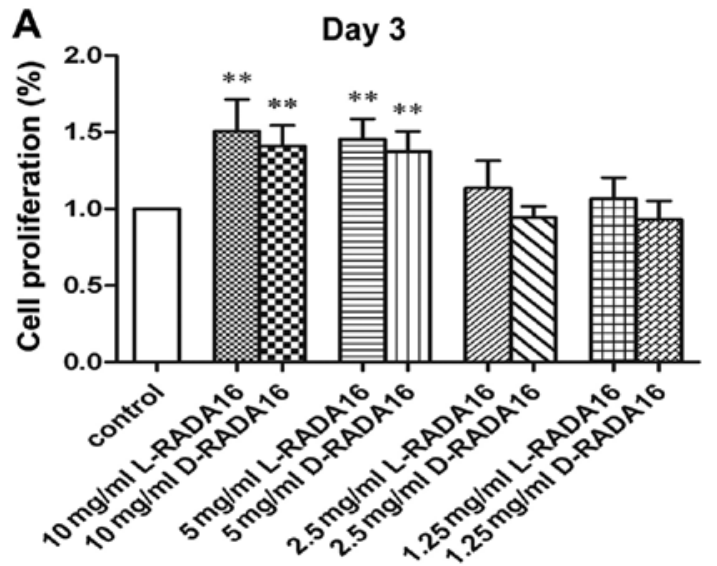

B Different concentration/controls

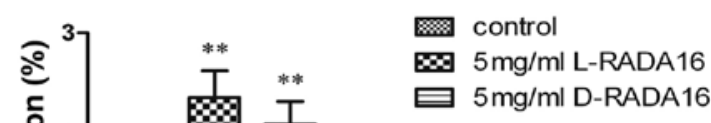

Figure 5. (A) MTT cell proliferation assays of BMSCs after 3 days of culture. Cells were seeded on tissue culture plate or chiral peptide scaffolds at various concentrations. The results are expressed as the cell proliferation rate compared to the OD value of the control. ${ }^{* * *} \mathrm{P}<0.01 \mathrm{vs.} \mathrm{control} \mathrm{group.} \mathrm{(B)} \mathrm{Effects} \mathrm{of} \mathrm{the} \mathrm{chiral} \mathrm{peptides}$ on cell proliferation after 5 and 7 days of culture. ${ }^{* *} \mathrm{P}<0.01$ vs. control group.
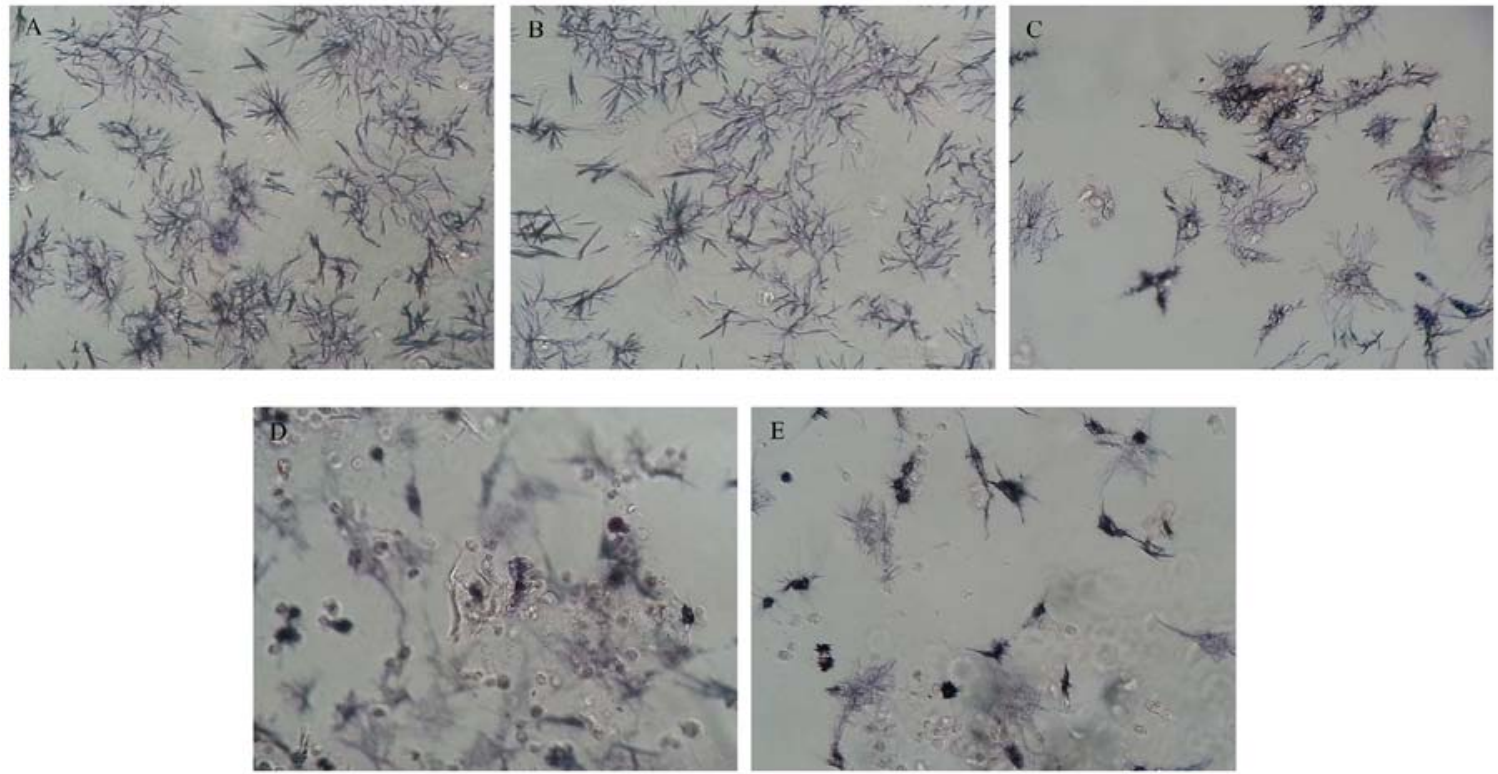

Figure 6. Observation of formazan dye crystals in 2D cell culture method as a control (A) and encapsulated in D-RADA16 at various concentrations [(B) $1.25 \mathrm{mg} / \mathrm{ml}$; (C) $2.5 \mathrm{mg} / \mathrm{ml}$; (D) $5.0 \mathrm{mg} / \mathrm{ml}$; (E) $10.0 \mathrm{mg} / \mathrm{ml}$ )] by light microscopy. The difference in the cells encapsulated in the 2D or 3D networks is evident. Original magnification, $\mathrm{x} 100$.

3 days of culture. The peptides at low concentrations of 1.25 or $2.5 \mathrm{mg} / \mathrm{ml}$ did not lead to a statistically significant difference in the cell proliferation rate in comparison to the control. By contrast, the peptides at high concentrations of 5 or $10 \mathrm{mg} / \mathrm{ml}$ led to a statistically significant difference in the cell proliferation rate in comparison to the control. These results indicated that the chiral peptide scaffolds at relatively high concentrations promoted cell proliferation. However, there was no statistically significant difference in the cell proliferation rate when the peptide at $5 \mathrm{mg} / \mathrm{ml}$ was compared to a higher concentration of the peptide at $10 \mathrm{mg} / \mathrm{ml}$. Therefore, the optimal concentration of the chiral peptides for cell culture was $5 \mathrm{mg} / \mathrm{ml}$, and this concentration was selected for use in further experiments.

Subsequently, BMSCs were grown on the chiral scaffolds at $5 \mathrm{mg} / \mathrm{ml}$ and the tissue culure plate for 5 and 7 days (Fig. 5B). Again, the chiral scaffolds possessed similar cell-scaffold bioactivity at each time point. Furthermore, significant differ- ences in the chiral scaffolds compared to the control were noted after 5 days of culture. Nonetheless, there were no significant differences in the chiral scaffolds compared to the control after 7 days of culture, and this can be explained by the fact that cells stop growing when they reach confluence. Since L-RADA16 has been proven to be non-toxic and non-immunogenic $(36,37)$, we hypothesized that D-RADA16 displayed no apparent toxicity in vitro under our present experimental conditions.

According to the protocol of MTT assay, after the cells were incubated for a given period of time, MTT solution was added to each sample and MTT was reduced by metabolically active cells to insoluble purple formazan dye crystals. We serendipitously observed the crystals under an inverted phase contrast microscope (Fig. 6). Of note, the seeded cell planes were out of focus, overlapping the focused plane, resulting in relatively fuzzy images when they were grown on D-RADA16 scaffolds at 5 and $10 \mathrm{mg} / \mathrm{ml}$. This fact suggests that the formazan exhibits 


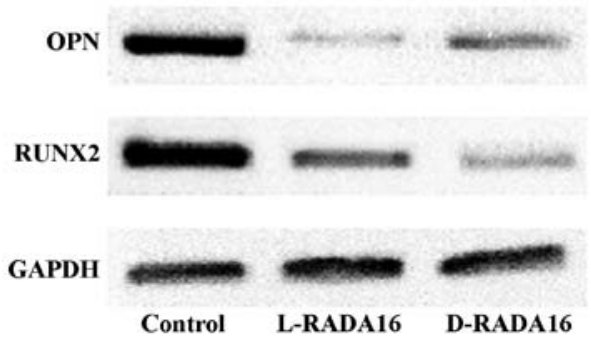

Figure 7. Representative blot of runt-related transcription factor 2 (RUNX2) and osteopotin (OPN) in monolayer and in RADA16 scaffolds after 7 days of culture. GADPH expression was used as an internal control $(n=3)$.

various $3 \mathrm{D}$ morphologies at relatively high concentrations of the D-RADA16 scaffold. By contrast, clear images can be captured when the cells were cultured in the concentrations of 0.125 and $2.5 \mathrm{mg} / \mathrm{ml}$, and the control, denoting that formazan retained 2D morphologies in the control and at low concentrations of the D-RADA16 scaffolds.

Effects of chiral peptide scaffolds on the osteogenic differentiation of BMSCs. The BMSCs were cultured in the SAP hydrogels to evaluate the osteogenic differentiation level at day 7. As a control, the BMSCs were cultured with the conventional 2D cell culture method. The relative expression level of RUNX2, osteopontin (OPN) was examined by western blot analysis. GAPDH was used as an internal control $(n=3)$. For all proteins, the two 3D scaffold groups possessed a significantly lower expression than the 2D culture control group (Fig. 7). The results indicated that the chiral SAP scaffolds did not promote the osteogenic differentiation of the BMSCs in vitro under our present experimental conditions.

Cell migration into 3D chiral peptide hydrogel scaffolds. In addition to the cell viability assay, the BMSCs were seeded in the chiral peptide hydrogels (Fig. 8A-D) and the tissue culture plate (Fig. 8E and F) to examine their 3D migration using calcein-AM staining. The confocal microscopy $3 \mathrm{D}$ reconstruction images revealed that cells migrated into the L-RADA16 (Fig. 8A and B) and D-RADA16 (Fig. 8C and D) scaffolds at $\sim 285$ and $\sim 186 \mu \mathrm{m}$, respectively. The results demonstrated that both of the two chiral peptides promoted cell migration into the 3D nanofiber scaffolds. They are consistent with those of a previous study on human adipose stem cells that migrated into 3D peptide hydrogel scaffolds (20).

Stability of peptides in proteinase $K$. In addition, the chiral peptides were also examined for enzymatic stability against proteinase $\mathrm{K}$, a potent and highly non-specific proteolytic enzyme. To avoid the effects of resistance due to hydrogelation, the concentration of each SAP was set at $0.2 \mathrm{mg} / \mathrm{ml}$, which is markedly lower than the critical gelation concentration of the hydrogel. As shown in Fig. 9, 75 and $60 \%$ of D-RADA16 remained after 2 and $6 \mathrm{~h}$ of incubation with proteinase $\mathrm{K}$ respectively, and $>50 \%$ remained after $24 \mathrm{~h}$. As for L-RADA16, $<25$ and $8 \%$ of SAP remained after 2 and $6 \mathrm{~h}$ of incubation respectively. These results illustrate that D-RADA16 exhibits stronger resistance to proteinase $\mathrm{K}$ digestion.

\section{Discussion}

In this study, we devised a SAP D-RADA16 made of only D-amino acids. It can self-assemble into interweaving nanofibers in aqueos solution, provide a suitable 3D network which allows the transport of oxygen, bioactive factors, nutrients and waste products. It serves further as a medium through which the diffusion of soluble factors and the migration of cells can occur. Firstly, CD spectroscopy reveaed that the D-RADA16 not only adopted a typical $\beta$-sheet structure, but was almost also a mirror image of the L-RADA16 spectrum. This denotes that D-RADA16 and L-RADA16 are enantiomers. The $\beta$-sheet structure is essential
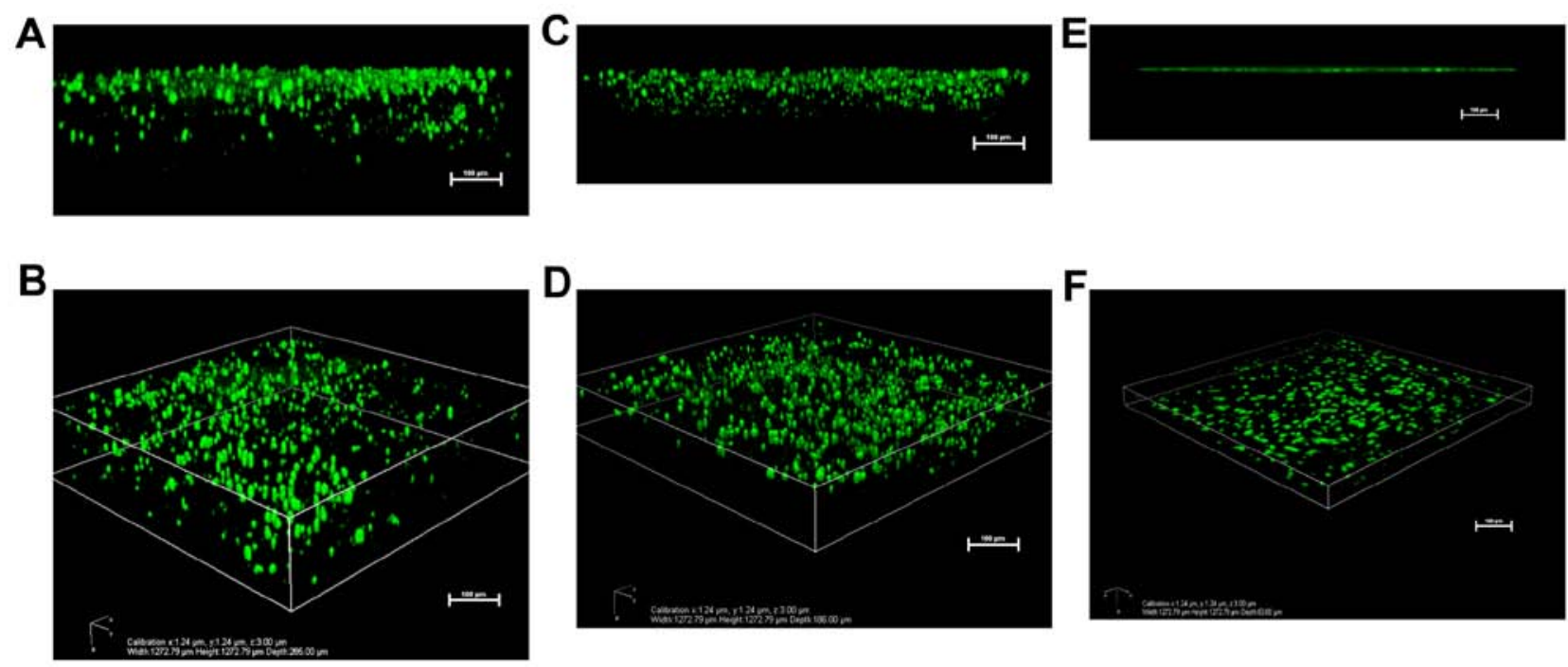

Figure 8. Calcein-AM staining of cell seeded on (A and B) L-RADA16, (C and D) D-RADA16 scaffolds, and (E and F) the tissue culture plate, respectively. (A, C and E) The horizontal view and (B, D and F) the 3D reconstruction view indicated that the cells were spontaneous migrated into the chiral scaffolds to several hundreds of micrometers in depth whereas the cells still on the surface of the plate in the 2D culture system, suggesting that the chiral scaffolds were able to provide suitable 3D culture environments for bone marrow-derived mesenchymal stem cells (BMSCs). Z-stack scanning was conducted with a step size of $3 \mu \mathrm{m}$. Step size $(3 \mu \mathrm{m})$ multiplied by the number of $\mathrm{z}$-series minus one equals the total thickness along the $\mathrm{z}$-direction. 


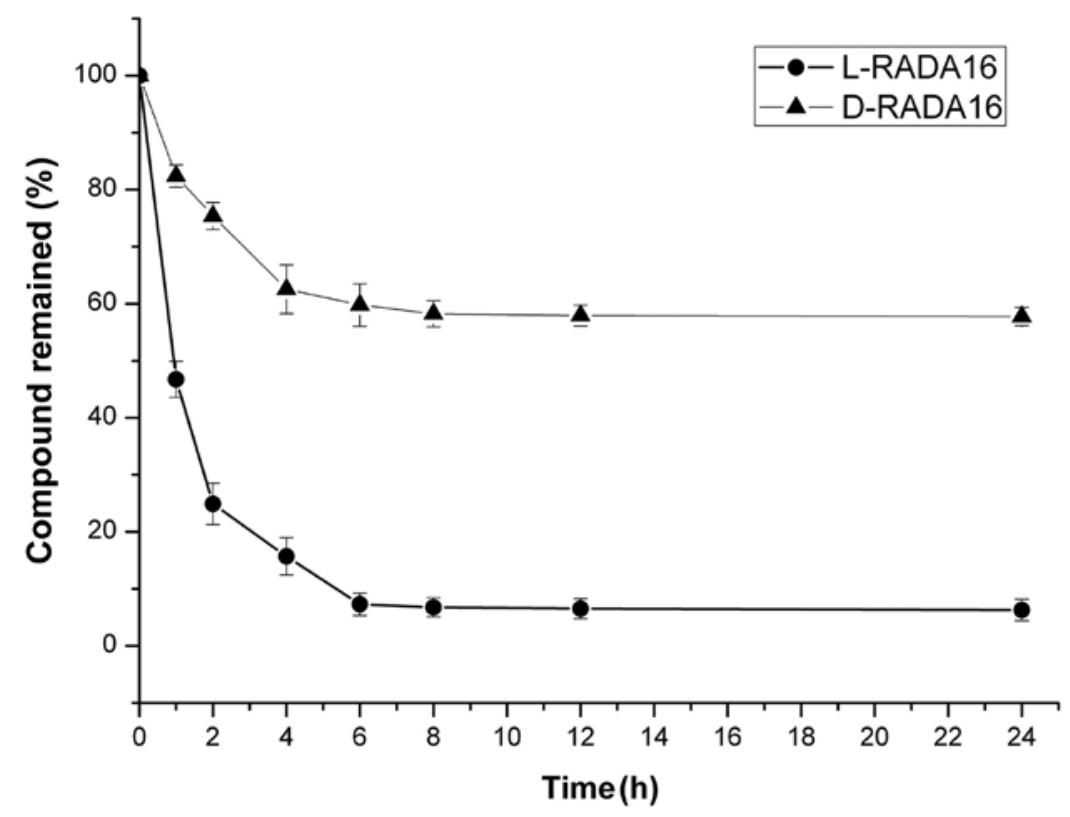

Figure 9. The decomposition of the chiral peptides in proteinase $\mathrm{K}$ for $24 \mathrm{~h}$.

for peptides in tissue engineering, as this structure has the ability of nanofiber formation and provides support to the cytoskeleton fiber (38). Previous studies have demonstrated that L-RADA16 can self-assemble into a stable $\beta$-sheet structure at physiologic conditions, forming interwoven nanofiber scaffolds that mimic the architecture of the ECM (34,39-41). Therefore, it is believable that D-RADA16 can form nanofiber scafflods as well. We have also performed a rheology experiment to investigate the mechanical property of the peptides hydrogelsrheology experiment (unpublished data). The values of storage moduli $\left(\mathrm{G}^{\prime}\right)$ were close to the values of the loss moduli $\left(\mathrm{G}^{\prime \prime}\right)$ when the concentration of L-RADA16 or D-RADA16 was $2.5 \mathrm{mg} / \mathrm{ml}$. Thus, they exhibited a liquid-like rheological behavior. When the concentration of the peptides hydrogels was $5.0 \mathrm{mg} / \mathrm{ml}$, the $\mathrm{G}^{\prime}$ values of the hydrogels were greater than the $G^{\prime \prime}$ values, suggesting the formation of true gels. The results revealed that the introduction of D-amino acids do not affect the gelation behavior of the SAP solution and the minimum gelation concentration of the peptides is $5.0 \mathrm{mg} / \mathrm{ml}$. Secondly, in the present study, the formation of uniform nanofibers of D-RADA16 observed by TEM (Fig. 4) indicated that the self-assembly process had been successfully attained and the designer SAP D-RADA16 shared the similar fine structure to L-RADA16. Finally, our study suggests that the chirality of peptides does not interfere with the molecular self-assembly nor the formation of well-defined nano-structures. This is in accordance with the findings of Luo et al (42), who evaluated the chiral peptides of EAK16.

Subsequently, we assessed whether the D-RADA16 scaffold, as the enantiomer of L-RADA16, can provide a suitable microenvironment for BMSC growth, proliferation, osteogenic differentiation and migration. We isolated BMSCs from the Sprague-Dawley rats and successfully cultured them in a 3D microenvironment on SAP scaffolds. BMSCs were selected as they are widely regarded as a stem cell for osteoblasts, differentiating along an osteogenic lineage when properly stimulated (43). Additionally, BMSCs are locally accessible at the bone microenvironment, being one of the first major cell types recruited to the surface of implanted bone biomaterials (44). These distinguishing properties render BMSCs a promising candidate for subsequent bone repair in vivo. Subsequently, MTT assay was carried out to assess the proliferation rate of the BMSCs seeded on the chiral scaffolds at different SAP concentrations and the traditional tissue culture plate. The results indicated that the chiral peptides at both 5.0 and $10.0 \mathrm{mg} / \mathrm{ml}$ promoted cell proliferation in comparison to the concentration of 1.25 and $2.5 \mathrm{mg} / \mathrm{ml}$ and the control. The effects of these peptides are mainly due to their self-assembling ability, which can form scaffolds to mimic the extracellular environment for cell growth, and the transport of oxygen, nutrients and waste products to take place in a $3 \mathrm{D}$ environment, while the amino acids of these peptides themselves do not interact with the cell $(14,37,45)$. We speculated that there was not a sufficient number of nanofibers to form a 3D environment in the low concentration of peptide solution, and thus it was similar to the conventional 2D culture. Conversely, the SAPs with relatively high concentrations holding enough interwoven nanofibers can form a stable 3D cell culture microenvironment. This is the reason why different concentrations of SAPs have differential effects on cell proliferation. However, no significant differences in the cell proliferation rate were obtained when the concentration of the peptide increased from 5.0 to $10.0 \mathrm{mg} / \mathrm{ml}$. It is plausible that there are enough nanofibers to form a scaffold network, mimicking 3D ECM at a concentration of $5.0 \mathrm{mg} / \mathrm{ml}$. Thereby, this concentration was selected for further experiments.

An interesting finding in MTT assay was that formazan crystals were inadvertently observed under an inverted phase contrast microscope. The formazan crystals, reduced by living cell enzymes, penetrated long-distances at relatively high concentrations of D-RADA16 (5.0 and $10.0 \mathrm{mg} / \mathrm{ml})$. We speculated that the D-RADA16 scaffolds were able to provide suitable 3D culture environments for BMSC adhesion and migration, which were identified by an optical microscope at the macro-level.

D-amino acid may be toxic to cells (46). Given that the degradation products of the D-form SAP consist of D-amino 
acid which may present complex toxicity profiles, in this study, cell viability was assessed in a relatively longer time duration by MTT assay. The results reveaked that D-RADA16 not only exerted no toxic effects, but also promoted BMSC growth and proliferation after 7 days of culture. The results confirmed that the D-RADA16 scaffold demonstrated excellent cellular biocompatibility in vitro. However, each peptide must first be screened in vivo carefully, in order to prevent the immunogenic response of the host animal (13). Biocompatibility and toxicity examinations are thus required to be carried out in numerous animal models to assess the safety of D-RADA16.

An ideal tissue engineered scaffold should provide a porous microstructure to regulate cell adhesion, proliferation and migration $(37,47)$. The 3D migration assay confirmed that BMSCs migrated inside the chiral scaffolds after 7 days of culture. On the contrary, cells remained restricted to the surface in the 2D control tissue culture plate since the cells could not migrate. These results indicate that the chiral SAP hydrogel scaffolds promote cell-cell interactions and provide a porous microstructure for cell migration, which is vital to facilitate tissue regeneration in the field of axon extension (13), angiogenesis (26), wound closure and epithelialization (21) and osteosis (28).

Although L-form SAPs have been successfully used to culture some cells in vitro (18,20-22,48-51), studies on larger constructs corresponding to clinical applications are far from being satisfactory. One of the main reasons is that the L-form peptides are susceptible to protease degradation, which lead to long-term instability in vivo $(30,52)$, particularly use for drug delivery vehicles in pharmaceutical applications, neural repair and induced osteogenesis. The use of D-amino acids is a potential approach for protecting biologically active peptides from enzymatic decomposition. In this study, the chiral scaffolds were explored for their ability to resist proteinase $\mathrm{K}$ degradation. This study indicated that D-RADA16 scaffolds resisted the enzymatic hydrolysis catalyzed and exhibited high biostability compared to its L-form enantiomer. This agrees with the findings of previous studies that peptide synthesized from D-amino acid can be exceptionally effective in increasing the resistance towards proteolysis $(29,30,32,42,53)$.

Despite the hopeful findings posed above, the relative fragility is a major concern for the D-RADA16 hydrogel. We are currently exploring the ability of coating D-RADA16 on hydroxyapatite substrate to increase the stiffness and modifying it with functional ligands to boost the bioactivity. Moreover, the more in depth mechanism of self-assembly is incompletely understood, and it requires under further investigation.

In conclusion, we in this study, we introduced a designer SAP D-RADA16 and successfully constructed a 3D culture microenvironment mimicking the ECM which supports rat BMSC growth and migration. D-RADA16, made of D-amino acid, can undergo self-assembly to form interweaving nanofiber scaffolds, and it exhibits high resistance against enzymatic hydrolysis catalyzed by proteinase $\mathrm{K}$ compared to its chiral counterpart peptide, L-RADA16. Additionally, D-RADA16 and L-RADA16 exhibited similar bioactivity and biocompatibility in spite of their chiral differences. Beyond 3D cell culture, D-RADA16 hydrogel scaffolds may have potential for use in long-term clinical applications in controlled drug delivery and neural repair, and may be able to counteract anatomical defects in bone regeneration and repair.

\section{Acknowledgements}

This study was supported by the National Natural Science Foundation of China (NSFC, no. 81472057).

\section{References}

1. Place ES, Evans ND and Stevens MM: Complexity in biomaterials for tissue engineering. Nat Mater 8: 457-470, 2009.

2. Owen SC and Shoichet MS: Design of three-dimensional biomimetic scaffolds. J Biomed Mater Res A 94: 1321-1331, 2010.

3. Oh JK: Engineering of nanometer-sized cross-linked hydrogels for biomedical applications. Can J Chem 88: 173-184, 2009.

4. Lutolf MP: Biomaterials: Spotlight on hydrogels. Nat Mater 8: 451-453, 2009.

5. Zhu J: Bioactive modification of poly(ethylene glycol) hydrogels for tissue engineering. Biomaterials 31: 4639-4656, 2010.

6. Geckil H, Xu F, Zhang X, Moon S and Demirci U: Engineering hydrogels as extracellular matrix mimics. Nanomedicine (Lond) 5: 469-484, 2010.

7. Liu SQ, Tay R, Khan M, Rachel Ee PL, Hedrick JL and Yang YY: Synthetic hydrogels for controlled stem cell differentiation. Soft Matter 6: 67-81, 2010.

8. Hosseinkhani H, Hosseinkhani M, Tian F, Kobayashi H and Tabata Y: Osteogenic differentiation of mesenchymal stem cells in self-assembled peptide-amphiphile nanofibers. Biomaterials 27: 4079-4086, 2006.

9. Cunha C, Panseri S, Villa O, Silva D and Gelain F: 3D culture of adult mouse neural stem cells within functionalized selfassembling peptide scaffolds. Int J Nanomedicine 6: 943-955, 2011.

10. Saltzman WM and Olbricht WL: Building drug delivery into tissue engineering. Nat Rev Drug Discov 1: 177-186, 2002.

11. Kretlow JD, Klouda L and Mikos AG: Injectable matrices and scaffolds for drug delivery in tissue engineering. Adv Drug Deliv Rev 59: 263-273, 2007.

12. Tan $\mathrm{H}$ and Marra KG: Injectable, biodegradable hydrogels for tissue engineering applications. Materials (Basel) 3: 1746-1767, 2010.

13. Zhang S: Fabrication of novel biomaterials through molecular self-assembly. Nat Biotechnol 21: 1171-1178, 2003.

14. He B, Yuan X and Jiang D: Molecular self-assembly guides the fabrication of peptide nanofiber scaffolds for nerve repair. RSC Advances 4: 23610-23621, 2014.

15. Zhang S, Holmes T, Lockshin C and Rich A: Spontaneous assembly of a self-complementary oligopeptide to form a stable macroscopic membrane. Proc Natl Acad Sci USA 90: 3334-3338, 1993.

16. Holmes TC, de Lacalle S, Su X, Liu G, Rich A and Zhang S: Extensive neurite outgrowth and active synapse formation on self-assembling peptide scaffolds. Proc Natl Acad Sci USA 97: 6728-6733, 2000.

17. Hamada K, Hirose M, Yamashita T and Ohgushi H: Spatial distribution of mineralized bone matrix produced by marrow mesenchymal stem cells in self-assembling peptide hydrogel scaffold. J Biomed Mater Res A 84: 128-136, 2008.

18. Horii A, Wang X, Gelain F and Zhang S: Biological designer self-assembling peptide nanofiber scaffolds significantly enhance osteoblast proliferation, differentiation and 3-D migration. PLoS One 2: e190, 2007.

19. Koutsopoulos $S$ and Zhang S: Long-term three-dimensional neural tissue cultures in functionalized self-assembling peptide hydrogels, matrigel and collagen I. Acta Biomater 9: 5162-5169, 2013.

20. Liu X, Wang X, Wang X, Ren H, He J, Qiao L and Cui FZ: Functionalized self-assembling peptide nanofiber hydrogels mimic stem cell niche to control human adipose stem cell behavior in vitro. Acta Biomater 9: 6798-6805, 2013.

21. Bradshaw M, Ho D, Fear MW, Gelain F, Wood FM and Iyer KS: Designer self-assembling hydrogel scaffolds can impact skin cell proliferation and migration. Sci Rep 4: 6903, 2014.

22. Wang B, Sun C, Shao Z, Yang S, Che B, Wu Q and Liu J: Designer self-assembling peptide nanofiber scaffolds containing link protein N-terminal peptide induce chondrogenesis of rabbit bone marrow stem cells. Biomed Res Int 2014: 421954, 2014.

23. Kisiday J, Jin M, Kurz B, Hung H, Semino C, Zhang S and Grodzinsky AJ: Self-assembling peptide hydrogel fosters chondrocyte extracellular matrix production and cell division: Implications for cartilage tissue repair. Proc Natl Acad Sci USA 99: 9996-10001, 2002.

24. Davis ME, Motion JPM, Narmoneva DA, Takahashi T, Hakuno D, Kamm RD, Zhang S and Lee RT: Injectable self-assembling peptide nanofibers create intramyocardial microenvironments for endothelial cells. Circulation 111: 442-450, 2005. 
25. Wang B, Wu Y, Shao Z, Yang S, Che B, Sun C, Ma Z and Zhang Y: Functionalized self-assembling peptide nanofiber hydrogel as a scaffold for rabbit nucleus pulposus cells. J Biomed Mater Res A 100: 646-653, 2012.

26. Liu X, Wang X, Horii A, Wang X, Qiao L, Zhang S and Cui FZ: In vivo studies on angiogenic activity of two designer selfassembling peptide scaffold hydrogels in the chicken embryo chorioallantoic membrane. Nanoscale 4: 2720-2727, 2012.

27. Soler-Botija C, Bagó JR, Llucià-Valldeperas A, Vallés-Lluch A, Castells-Sala C, Martínez-Ramos C, Fernández-Muiños T, Chachques JC, Pradas MM, Semino CE, et al: Engineered 3D bioimplants using elastomeric scaffold, self-assembling peptide hydrogel, and adipose tissue-derived progenitor cells for cardiac regeneration. Am J Transl Res 6: 291-301, 2014.

28. Wu M, Ye Z, Zhu H and Zhao X: Self-assembling peptide nanofibrous hydrogel on immediate hemostasis and accelerative osteosis. Biomacromolecules 16: 3112-3118, 2015.

29. Li X,Du X,Li J, Gao Y,Pan Y, Shi J,Zhou N and Xu B: Introducing D-amino acid or simple glycoside into small peptides to enable supramolecular hydrogelators to resist proteolysis. Langmuir 28: 13512-13517, 2012.

30. Tugyi R, Uray K, Iván D, Fellinger E, Perkins A and Hudecz F: Partial D-amino acid substitution: Improved enzymatic stability and preserved $\mathrm{Ab}$ recognition of a MUC2 epitope peptide. Proc Natl Acad Sci USA 102: 413-418, 2005.

31. Welch BD, VanDemark AP, Heroux A, Hill CP and Kay MS Potent D-peptide inhibitors of HIV-1 entry. Proc Natl Acad Sci USA 104: 16828-16833, 2007.

32. Liang G, Yang Z, Zhang R, Li L, Fan Y, Kuang Y, Gao Y, Wang T, Lu WW and Xu B: Supramolecular hydrogel of a D-amino acid dipeptide for controlled drug release in vivo. Langmuir 25 8419-8422, 2009.

33. Lennon DP, Haynesworth SE, Young RG, Dennis JE and Caplan AI: A chemically defined medium supports in vitro proliferation and maintains the osteochondral potential of rat marrow-derived mesenchymal stem cells. Exp Cell Res 219: 211-222, 1995

34. Yokoi H, Kinoshita $\mathrm{T}$ and Zhang S: Dynamic reassembly of peptide RADA16 nanofiber scaffold. Proc Natl Acad Sci USA 102: 8414-8419, 2005.

35. Hauser CAE and Zhang S: Designer self-assembling peptide nanofiber biological materials. Chem Soc Rev 39: 2780-2790, 2010.

36. Tang C, Shao X, Sun B, Huang W and Zhao X: The effect of self-assembling peptide RADA16-I on the growth of human leukemia cells in vitro and in nude mice. Int J Mol Sci 10: 2136-2145, 2009.

37. Nune M, Kumaraswamy P, Krishnan UM and Sethuraman S: Self-assembling peptide nanofibrous scaffolds for tissue engineering: Novel approaches and strategies for effective functional regeneration. Curr Protein Pept Sci 14: 70-84, 2013.

38. Tavakol S, Saber R, Hoveizi E, Aligholi H, Ai J and Rezayat SM: Chimeric self-assembling nanofiber containing bone marrow homing peptide's motif induces motor neuron recovery in animal model of chronic spinal cord injury; An in vitro and in vivo investigation. Mol Neurobiol 53: 3298-3308, 2016.
39. Taraballi F, Campione M, Sassella A, Vescovi A, Paleari A, Hwangc W and Gelain F: Effect of functionalization on the self-assembling propensity of $\beta$-sheet forming peptides. Soft Matter 5: 660-668, 2009.

40. Cormier AR, Pang X, Zimmerman MI, Zhou HX and Paravastu AK: Molecular structure of RADA16-I designer selfassembling peptide nanofibers. ACS Nano 7: 7562-7572, 2013.

41. Ravichandran R, Griffith M and Phopase J: Applications of selfassembling peptide scaffolds in regenerative medicine: The way to the clinic. J Mater Chem B Mater Biol Med 2: 8466-8478, 2014.

42. Luo Z, Yue Y, Zhang Y, Yuan X, Gong J, Wang L, He B, Liu Z, Sun Y, Liu J, et al: Designer D-form self-assembling peptide nanofiber scaffolds for 3-dimensional cell cultures. Biomaterials 34: 4902-4913, 2013.

43. Anderson JM, Patterson JL, Vines JB, Javed A, Gilbert SR and Jun HW: Biphasic peptide amphiphile nanomatrix embedded with hydroxyapatite nanoparticles for stimulated osteoinductive response. ACS Nano 5: 9463-9479, 2011.

44. Pittenger MF, Mackay AM, Beck SC, Jaiswal RK, Douglas R, Mosca JD, Moorman MA, Simonetti DW, Craig S and Marshak DR: Multilineage potential of adult human mesenchymal stem cells. Science 284: 143-147, 1999.

45. Hosseinkhani H, Hong PD and Yu DS: Self-assembled proteins and peptides for regenerative medicine. Chem Rev 113 4837-4861, 2013.

46. Friedman M: Chemistry, nutrition, and microbiology of D-amino acids. J Agric Food Chem 47: 3457-3479, 1999.

47. Bergmeister H, Schreiber C, Grasl C, Walter I, Plasenzotti R, Stoiber M, Bernhard D and Schima H: Healing characteristics of electrospun polyurethane grafts with various porosities. Acta Biomater 9: 6032-6040, 2013.

48. Zhang F, Shi GS, Ren LF, Hu FQ, Li SL and Xie ZJ: Designer self-assembling peptide scaffold stimulates pre-osteoblast attachment, spreading and proliferation. J Mater Sci Mater Med 20: 1475-1481, 2009.

49. Ozeki M, Kuroda S, Kon K and Kasugai S: Differentiation of bone marrow stromal cells into osteoblasts in a self-assembling peptide hydrogel: In vitro and in vivo studies. J Biomater Appl 25: 663-684, 2011.

50. Ni N, Hu Y, Ren H, Luo C, Li P, Wan JB and Su H: Selfassembling peptide nanofiber scaffolds enhance dopaminergic differentiation of mouse pluripotent stem cells in 3-dimensional culture. PLoS One 8: e84504, 2013.

51. Lu T, Chen T, Zhai Y, Ma Y and Xiao Y: Designer functionalized self-assembling peptide scaffolds for adhesion, proliferation, and differentiation of MC3T3-E1. Soft Mater 12: 79-87, 2013.

52. Nagy KJ, Giano MC, Jin A, Pochan DJ and Schneider JP Enhanced mechanical rigidity of hydrogels formed from enantiomeric peptide assemblies. J Am Chem Soc 133: 14975-14977, 2011.

53. Luo Z, Zhao X and Zhang S: Self-organization of a chiral D-EAK16 designer peptide into a 3D nanofiber scaffold. Macromol Biosci 8: 785-791, 2008. 